\title{
Pengembangan Aplikasi Perpustakaan Berbasis Web untuk Peningkatan Kualitas Sirkulasi Pustaka di SMAN 1 Jombang
}

\author{
Dwi Ratna Sulistyaningrum, Budi Setiyono, Didik Khusnul Arif, Daryono Budi Utomo, Valeriana \\ Lukitosari, Lukman Hanafi \\ Departemen Matematika, Fakultas Sains dan Analitika Data, Institut Teknologi Sepuluh Nopember \\ Jl. Arif Rahman Hakim, Surabaya 60111, Indonesia
}

\begin{abstract}
ARTICLE INFO
Received: 2020-12-17

Revised: 2021-01-23

Accepted: 2021-03-03

Keywords:

Code ignaiter, Library, MySQL, Waterfall, Web

\section{ABSTRACT}

The library is a learning infrastructure that must be available in every school. Libraries provide information and knowledge needed by students. The development of technology and information is expected to have an impact, namely the efficiency and effectiveness of the implementation of work. One way is to change the manual system into a computer-assisted system supported by internet technology. In this community service activity, a web-based library application has been designed and built at SMAN 1 Jombang. Application development uses the Waterfall model which consists of 4 stages, namely system requirements analysis, system design, implementation, and maintenance. The library application is built using the Code Ignaiter framework with the Hypertext Pre-Processor (PHP) programming language while the database uses MySQL.The benefit of this application is to address the needs of students for book searches and book ordering, while for school library officers it manages the circulation of book borrowing and reporting. The result of community service that has been implemented is a Web-based library application at SMA Negeri 1 Jombang to improve the quality of library management.
\end{abstract}

(C)2021 Published by University of Merdeka Malang. This is an open access article distributed under the CC BY-SA 4.0 license (https://creativecommons.org/licenses/by-sa/4.0/)

How to cite: Sulistyaningrum, D. R., Setiyono, B., Arif, D. K., Utomo, D. B., Lukitosari, V., \& Hanafi, L. (2021). Pengembangan Aplikasi Perpustakaan Berbasis Web untuk Peningkatan Kualitas Sirkulasi Pustaka di SMAN 1 Jombang. Abdimas: Jurnal Pengabdian Masyarakat Universitas Merdeka Malang, 6(2), 305-313. https://doi.org/10.26905/abdimas.v6i2.5173

\section{PENDAHULUAN}

Media informasi dan telekomunikasi mempunyai peranan penting pada proses transaksi informasi, barang, dan jasa. Perkembangan teknologi informasi yang pesat sangat bermanfaat pada berbagai bidang, seperti pemerintahan, ekonomi, pendidikan, militer, pariwisata, dan lain-lain. Pada bidang pendidikan salah satu faktor pendukung adalah keberadaan perpustakaan sekolah sebagai penyedia informasi dan ilmu pengetahuan. 
ABDIMAS: Jurnal Pengabdian Masyarakat Universitas Merdeka Malang

Volume 6, No. 2, May 2021: 305-313

Pada Undang-Undang No. 43/2007 tentang Perpustakaan dikatakan bahwa perpustakaan adalah institusi profesional dengan menggunakan sistem standar untuk mengelola karya-karya tulis, rekam, dan cetak untuk memenuhi kebutuhan pendidikan, penelitian, pelestarian, dan informasi. Dalam UndangUndang tersebut juga disebutkan setiap perpustakaan dapat mengembangkan sistem aplikasi perpustakaan mengikuti perkembangan tekonologi informasi dan komunikasi.

Perpustakaan sekolah merupakan prasarana belajar yang harus tersedia pada setiap sekolah. Perpustakaan menyediakan informasi dan ilmu pengetahuan yang diperlukan oleh peserta didik. Tujuan pendirian perpustakaan sekolah adalah untuk mendukung tercapainya tujuan sekolah, seperti yang digariskan dalam kurikulum sekolah (Rohmah et al., 2019; Rahmawati \& Bachtiar, 2018). Pada saat ini, sistem pengelolaan dan pelayanan pada perpustakaan sekolah masih bersifat manual sehingga proses pengelolaan dan pelayanan tidak efisien. Apabila suatu perpustakaan mempunyai ribuan koleksi pustaka, ribuan anggota serta jumlah transaksi peminjaman dan pengembalian yang banyak maka akan memerlukan waktu lama dalam proses pengelolaan dan pelayanan terhadap pemustaka (Nugraha, 2014).

Suatu aplikasi berbasis web adalah suatu perangkat lunak yang berbasis pada teknologi dan standar World Wide Web Consortium (W3C) (Arief, 2011; Kustiyahningsih \& Rosa, 2011). Pada perangkat lunak tersebut menyediakan berbagai konten dan layanan melalui antar muka pengguna dan browser web.

SMAN 1 Jombang merupakan salah satu sekolah yang berada di Jombang, Jawa Timur dan mempunyai total siswa kelas 11 sampai dengan kelas 12 sekitar 500 siswa. Sekolah ini merupakan salah satu sekolah terbaik di Kota Jombang. Pengelolaan perpustakaan sekolah SMAN 1 Jombang masih secara manual khususnya dalam transaksi peminjaman dan pengembalian buku, sehingga dikuatirkan terjadi kesalahan dalam hal pencatatan sirkulasi koleksi yang disebabkan oleh data buku tidak didokumentasi dengan baik.

Berdasarkan permasalahan tersebut, maka adanya kegiatan pengabdian pada masyarakat ini bertujuan untuk meningkatkan kualitas pengelolaan perpustakaan dengan cara membuat aplikasi perpustakaan berbasis web. Makalah ini membahas tentang kegiatan pengabdian pada masyarakat di SMAN 1 Jombang dalam rangka meningkatkan kualitas pengelolaan perpustakaan melalui pembuatan aplikasi perpustakaan berbasis web. Pengembangan aplikasi dimulai dengan survei tentang kebutuhan aplikasi, pembuatan aplikasi, pengujian aplikasi dan perawatan. Manfaat dari aplikasi perpustakaan berbasis website ini adalah membantu petugas perpustakaan dalam mengelola sirkulasi buku dan pelaporan.

\section{METODE}

\section{Objek dan lokasi pengabdian}

Objek pengabdian pada masyarakat ini adalah tentang pembuatan aplikasi perpustakaan berbasis web. Sedangkan lokasi pengabdian di Perpustakaan SMAN 1 Jombang. Metodologi pengabdian masya- 
rakat dimulai dengan tim pengabdi melakukan survei langsung ke Perpustakaan SMAN 1 Jombang, kemudian dilanjutkan dengan pembuatan aplikasi perpustakaan.

\section{Model}

Teknik analisis data dalam pembuatan aplikasi Perpustakaan SMAN 1 Jombang menggunakan pemodelan dengan metode waterfall, yang terdiri dari beberapa tahapan (Pressman \& Maxim, 2014; Rohmah et al., 2019; Susanti, 2016) di antaranya, (1) Analisis kebutuhan. Proses mengumpulkan kebutuhankebutuhan dari pengguna aplikasi. Berdasarkan daftar kebutuhan pengguna, kemudian dilakukan analisis dan pendefinisian kebutuhan-kebutuhan yang harus disediakan oleh aplikasi yang dibuat; (2) Perancangan aplikasi. Berdasarkan hasil dari pertama kemudian dibuat desain sistem. Setelah desain telah lengkap, pembuatan perangkat lunak sistem informasi perpustakaan dapat dibuat. Pembuatan sistem menggunakan software pendukung seperti Visual Studio, web broser Google Chrome, dan XAMPP sebagai software utama pembuatan sistem berbasis web serta bahasa pemrograman yaitu PHP/ MySQL. Hasil dari proses ini adalah desain yang lengkap; (3) Implementasi dan pengujian. Melakukan implementasi desain sistem pada sistem informasi berbasis web, yaitu dengan mentransformasikan desain menjadi kode-kode program dan menguji kelayakan hasilnya. Pengujian dilakukan pada setiap unit proses, yaitu penyesuaian hasil program dengan desain sistem; (4) Integrasi dan sistem testing. Melakukan penyatuan dari setiap unit program yang dibangun. Kemudian dilakukan pengujian sistem secara menyeluruh; (5) Operasi dan perawatan. Proses terakhir adalah melakukan ujiacoba hasil program dengan menggunakan data riil dan kondisi riil. Pengoperasian dilakukan menyeluruh untuk kesesuaian hasil program dengan desain sistem. Apabila ada hasil pengoperasian yang tidak sesuai maka dilakukan penyesuaian (maintenance).

\section{Analisis}

\section{Analisis prosedur}

Berdasarkan hasil analisis kebutuhan dan penelitian awal, terdapat beberapa prosedur yang dilakukan dan diharapkan pada Perpustakaan SMAN 1 Jombang, diantaranya: (1) Prosedur pencarian buku; (2) Prosedur peminjaman dan pengembalian buku; (3) Prosedur cetak laporan buku, peminjaman, pengembalian dan koleksi; (4) Prosedur penambahan koleksi buku dan anggota perpustakaan; (5) Prosedur penambahan kategori buku, lokasi buku, dan sejenisnya.

\section{Analisis kebutuhan fungsional}

Dari hasil user requirement, diperoleh hasil berupa kebutuhan user. Kebutuhan user dibedakan dalam dua jenis, yaitu kebutuhan fungsional dan kebutuhan non-fungsional. Tabel 1 menunjukkan daftar kebutuhan non-fungsionalitas aplikasi. Sedangkan kebutuhan fungsional aplikasi antara lain dirangkum dalam Tabel 2. 
ABDIMAS: Jurnal Pengabdian Masyarakat Universitas Merdeka Malang

Volume 6, No. 2, May 2021: 305-313

Tabel 1. Kebutuhan non-fungsionalitas aplikasi

\begin{tabular}{ll}
\hline \multicolumn{1}{c}{ Kebutuhan Non-Fungsionalitas } & \multicolumn{1}{c}{ Keterangan } \\
\hline Web server untuk hosting & Digunakan untuk menempatkan aplikasi agar bisa diakses secara online \\
Komputer client 1 & Digunakan untuk proses transaksi oleh petugas perpustakaan \\
Komputer client 2 & Digunakan siswa untuk searching koleksi yang akan dipinjam \\
Jaringan internet & Digunakan untuk komunikasi dengan sistem dan untuk operasional \\
\hline
\end{tabular}

Tabel 2. Kebutuhan fungsional aplikasi

\begin{tabular}{|c|c|}
\hline Kebutuhan Fungsional & Keterangan \\
\hline Pencarian/searching & $\begin{array}{l}\text { Modul ini digunakan untuk proses pencarian beberapa property, yaitu: } \\
\text { - Anggota } \\
\text { - Koleksi } \\
\text { - Transaksi } \\
\text { - Koleksi sudah dikembalikan } \\
\text { - Koleksi belum dikembalikan }\end{array}$ \\
\hline Manajemen data master & $\begin{array}{l}\text { Modul ini diperuntukan untuk manajemen data-data master, yang meliputi data anggota, } \\
\text { koleksi, lokasi, dan user. Manajemen data berupa: } \\
\text { - Insert } \\
\text { - Update } \\
\text { - Delete }\end{array}$ \\
\hline Manajemen transaksi & $\begin{array}{l}\text { Modul ini bertanggung jawab terkait proses transaksi yang terjadi pada sistem. Transaksi terdiri } \\
\text { dari: } \\
\text { - Transaksi peminjaman buku } \\
\text { - Transaksi pengembalian buku } \\
\text { - Transaksi pemesanan buku }\end{array}$ \\
\hline Manajemen laporan & Modul ini digunakan untuk membuat beberapa \\
\hline
\end{tabular}

\section{Desain}

Berdasarkan analisis user requirement diatas, selanjutnya dibuat desain sistem, yang meliputi desain database, desain menu, dan desain layouting.

\section{Desain database}

Desain database dibuat sedemikian rupa sehingga bisa memenuhi kebutuhan user. Desain Physical Data Model aplikasi perpustakaan mempunyai 12 tabel yaitu: (1) Tabel User; (2) Tabel Anggota; (3) Tabel Transaksi; (4) Tabel Detail_Transaksi; (5) Tabel User_grup; (6) Tabel Grup; (7) Tabel Inden; (8) Tabel Koleksi; (9) Tabel login_attemps; (10) Tabel Lokasi; (11) Tabel Katagori; dan (12) Tabel Harilibur. Tabel-tabel tersebut membentuk relasi antar tabel agar dapat terbangun sistem perpustakaan.

\section{Desain struktur menu}

Desain struktur menu dirancang agar alur penggunaan aplikasi yang mudah dipahami dan mudah digunakan. Rancangan struktur menu dari aplikasi perpustakaan dibagi menjadi 4 menu utama, yaitu Master, Transaksi, Laporan, dan Pengaturan. Gambar 1 menunjukkan detail dari masing-masing menu utama. 


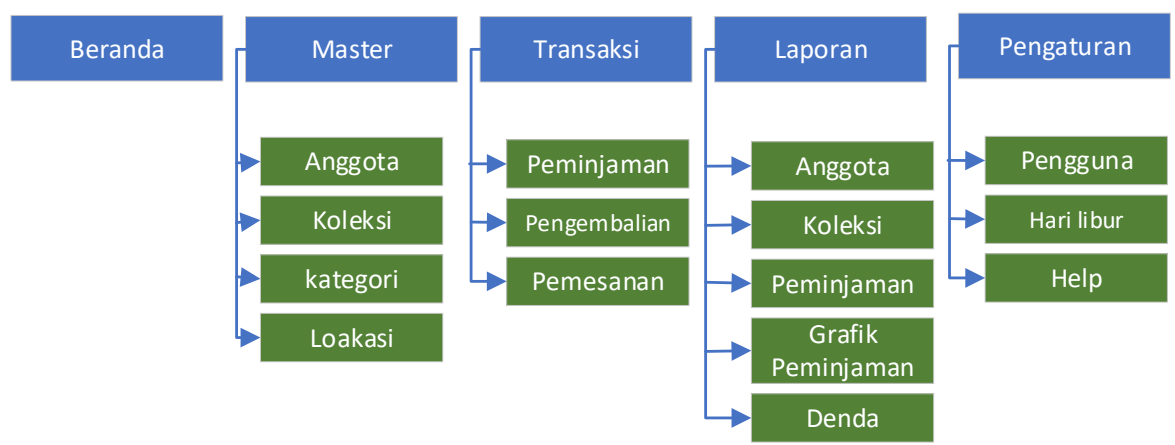

\section{Desain layout}

Gambar 1. Struktur menu

Desain layout digunakan untuk merancang tampilan secara visual. Pada dasarnya, area screen dibagi menjadi 3 bagian, yaitu untuk header, menu, dan gambar serta informasi yang sering diakses. Gambar desain layout dapat dilihat pada Gambar 2.

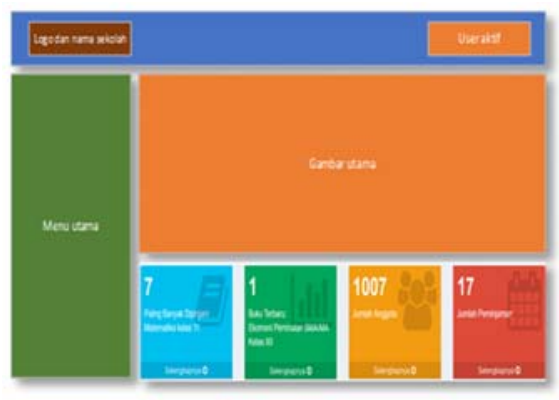

Gambar 2. Layout menu

\section{HASIL DAN PEMBAHASAN}

Hasil kegiatan pengabdian masyarakat ini adalah sebuah aplikasi perpustakaan yang akan membantu pihak pengelola perpustakaan untuk melakukan pengarsipan dan pelaporan sirkulasi buku dan pengguna. Kegiatan pengabdian dilaksanakan selama 6 bulan efektif dengan menyesuaikan terhadap Bulan Ramadhan dan Hari Raya Idul Fitri.

\section{Tahapan Pelaksanaan}

\section{Presentasi}

Pada tahap presentasi ini, tim pengabdi akan mempresentasikan tentang kegiatan yang akan dilakukan dan bentuk skenario kerjasama. Selain itu, juga diberikan gambaran contoh dari aplikasi perpustakaan yang akan dibuat. 
ABDIMAS: Jurnal Pengabdian Masyarakat Universitas Merdeka Malang

Volume 6, No. 2, May 2021: 305-313

\section{Analisis dan desain aplikasi}

Pada tahap ini ada dua kegiatan, yaitu analisis kebutuhan aplikasi dan desain aplikasi. Analisis kebutuhan aplikasi bertujuan mendapatkan informasi kebutuhan-kebutuhan dari pengguna aplikasi secara lengkap meliputi analisis kebutuhan prosedural dan fungsional. Sedangkan pada kegiatan desain sistem telah dihasilkan desain database, desain struktur menu dan desain layout.

\section{Implementasi dan uji coba}

Implementasi dilakukan dengan membuat kode-kode program menggunakan bahasa pemrograman PHP dan manajemen database MySQL seperti pada beberapa referensi sebelumnya (Indera, 2015; Renatha et al., 2015). Kode-kode tersebut merupakan transformasi hasil proses desain secara menyeluruh. Program yang dihasilkan langsung diuji coba menggunakan web browser pada server lokal. Proses implementasi dan pengujian akan terus berjalan sampai diperoleh kesusaian antara model, analisis kebutuhan fungsional, dan desain sistem. Framework yang digunakan adalah Code Ignaiter. Framework ini telah banyak digunakan pada pengembangan sistem berbasis web dikarenakan kemudahan dan kehandalan yang dimilikinya (Suhartini et al., 2020; Yahya, 2020; Oktami \& Mailoa, 2019).

Proses terakhir pada tahap implementasi adalah penyelarasan antara sistem yang dibuat dengan kondisi riil. Kemudian, dilakukan uploading sistem informasi perpustakaan pada situs daring. Tabel 3 menunjukkan daftar perangkat lunak yang digunakan untuk implementasi.

Tabel 3. Daftar perangkat lunak untuk implementasi

\begin{tabular}{lll}
\hline \multicolumn{1}{c}{ Proses } & \multicolumn{1}{c}{ Software } & \multicolumn{1}{c}{ Keterangan } \\
\hline Framework & Code Ignaiter & Framework pengembangan sistem \\
Base Browser & Mozila Firefox & Browser utama yang digunakan pada saat develop \\
Database & MySQ & Database yang digunakan \\
Webserver & Apache & Webserver \\
Tool tambahan & Bootstrap, Java Script, CSS & Digunakan untuk tampilan dan visualisasi \\
\hline
\end{tabular}

Beberapa contoh tampilan sistem informasi Perpustakaan SMAN 1 Jombang diberikan pada Gambar 3, Gambar 4, Gambar 5 dan Gambar 6.

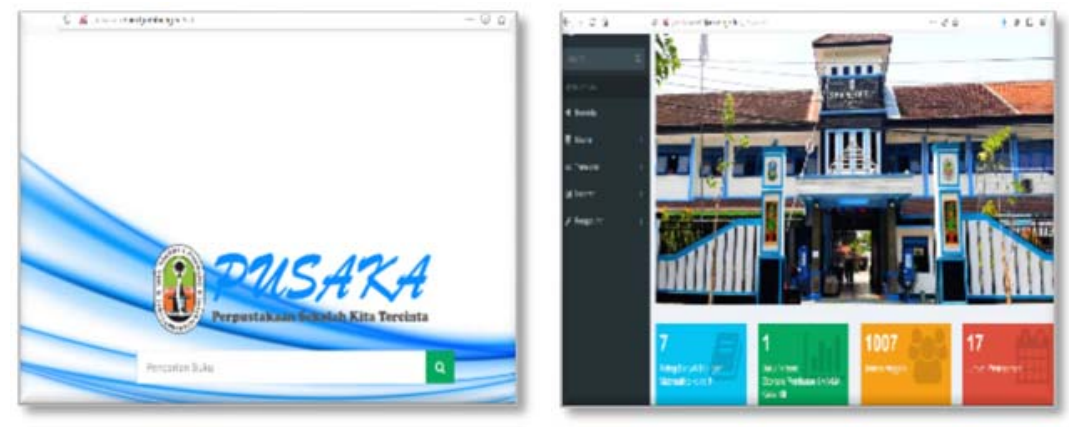

Gambar 3. Halaman akun masuk

Gambar 4. Halaman utama akun masuk 

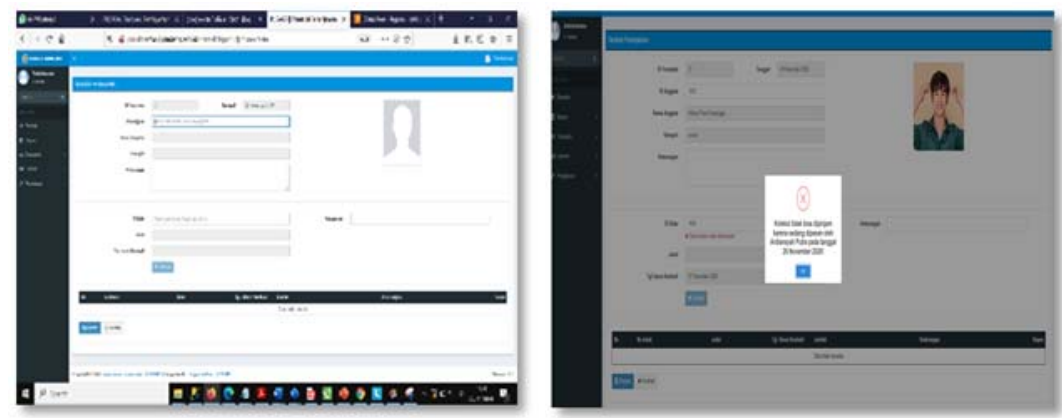

Gambar 5. Transaksi peminjaman

Gambar 6. Kondisi apabila koleksi sudah dipesan

\section{Pembuatan buku panduan}

Setelah uji coba aplikasi maka tim pengabdi mengerjakan pembuatan buku panduan pemakaian aplikasi perpustakaan. Buku panduan berfungsi untuk membantu pengguna mengoperasikan aplikasi perpustakaan sehingga pengguna dapat memakai aplikasi tanpa kesulitan.

\section{Pelatihan operasional aplikasi}

Pada tahap ini, tim pengabdi memberikan pelatihan secara langsung kepada pengguna aplikasi tentang tata cara pemakaian aplikasi perpustakaan. Pada kegiatan pelatihan ini juga dilakukan uji coba aplikasi secara nyata di perpustakaan sekolah.

\section{Pendampingan dan maintenance}

Tim pengabdi masih melakukan pendampingan dan maintenance dari aplikasi yang sudah bisa digunakan oleh siswa. Tujuan dari pendampingan ini adalah untuk memberikan solusi apabila terjadi kendala pada saat pengoperasian aplikasi.

\section{Pembahasan}

Pelaksanaan kegiatan pengabdian ini sudah berjalan sesuai strategi dan perencanaan yang dituangkan dalam bab sebelumnya. Pada dasarnya, keberhasilan pengabdian ini belum bisa diukur secara detail, dikarenakan pada masa pandemi ini proses belajar mengajar di SMAN 1 Jombang dan sekolah-sekolah lainnya masih dilakukan secara online. Hal ini juga berdampak pada sirkulasi buku di perpusakaan relatif belum ada. Namun demikian, ada beberapa hal yang bisa diamati perubahannya, yang dirangkum dalam Tabel 4.

Terdapat dua faktor yang mendukung terlaksananya kegiatan pengabdian pada masyarakat ini adalah: (1) Dukungan oleh pihak SMAN 1 Jombang dalam memberikan sumber informasi dan fasilitas tempat pelaksanaan; (2) Partisipasi aktif dari siswa dan guru saat kegiatan berlangsung. 
ABDIMAS: Jurnal Pengabdian Masyarakat Universitas Merdeka Malang

Volume 6, No. 2, May 2021: 305-313

Faktor kendala yang terjadi pada saat pelaksanaan aktivitas program pengabdian pada masyarakat ini adalah: (1) Kondisi pandemi COVID-19 mengakibatkan kesulitan interaksi secara langsung dengan pihak mitra; (2) Pada saat simulasi sistem ada kendala transfer pengetahuan.

Tabel 4. Perubahan yang teramati

\begin{tabular}{ll}
\hline \multicolumn{1}{c}{ Sebelum } & \multicolumn{1}{c}{ Sesudah } \\
\hline $\begin{array}{l}\text { Cetak kartu anggota secara terpisah dan penomoran anggota } \\
\text { dilakukan secara manual }\end{array}$ & $\begin{array}{l}\text { Kartu anggota dapat dicetak otomatis melalui sistem yang } \\
\text { dibangun disertai dengan barcode }\end{array}$ \\
$\begin{array}{l}\text { Pengelolaan koleksi masih secara manual, sehingga } \\
\text { inventarisasi dan melihat ketersediaan buku cukup sulit dan } \\
\text { lama }\end{array}$ & $\begin{array}{l}\text { Koleksi di manajemen secara digital. Disamping itu, identifikasi } \\
\text { setiap koleksi dilakukan dengan mencetak barcode yang dapat } \\
\text { dilakukan oleh sistem }\end{array}$ \\
$\begin{array}{l}\text { Proses peminjaman yang dilakukan oleh siswa dilakukan } \\
\text { dengan cara mengisi buku secara manual }\end{array}$ & $\begin{array}{l}\text { Proses peminjaman dilakukan secara koputerisasi, siswa tinggal } \\
\text { menunjukkan kartu anggota, kemudian dipindai (barcode), dan } \\
\text { buku yang dipinjam juga dipindai (barcode) }\end{array}$ \\
$\begin{array}{l}\text { Siswa tidak bisa melihat ketersediaan buku } \\
\begin{array}{l}\text { Jika koleksi tidak ada/terpinjam, siswa tidak bisa melakukan } \\
\text { pemesanan }\end{array}\end{array}$ & $\begin{array}{l}\text { Siswa daoat melihat ketersediaan buku secara otomatis } \\
\text { dipinjamnya sedang dipinjam oleh siswa lain. }\end{array}$ \\
$\begin{array}{l}\text { Pihak perpustakaan kesulitan untuk membuat laporan terkait } \\
\text { buku yang masih dalam peminjaman, buku yang sering } \\
\text { dipinjam, dan lain-lain }\end{array}$ & $\begin{array}{l}\text { Laporan dapat dengan mudah dibuat oleh pengelola } \\
\text { perpustakaan, sehingga akan memudahkan untuk analisis data } \\
\text { jika diperlukan. }\end{array}$ \\
\hline
\end{tabular}

\section{SIMPULAN DAN SARAN}

Tujuan dari kegiatan pengabdian pada masyarakat ini adalah untuk meningkatkan kualitas pengelolaan perpustakaan di SMAN 1 Jombang melalui aplikasi perpustakaan berbasis web. Aplikasi Perpustakaan SMAN 1 Jombang ini sangat bermanfaat untuk anggota/siswa untuk melihat daftar koleksi buku dan pengajuan pendaftaran anggota menggunakan jaringan internet. Pustakawan dapat melakukan transaksi peminjaman dan pengembalian dengan mudah dan cepat, misalnya jika koleksi dalam status dipinjam oleh anggota lain. Pengelolaan data buku, data transaksi, dan laporan transaksi dapat dilaporkan kapanpun diinginkan.

Perlu adanya sosialisasi penggunaan aplikasi perpustakaan kepada seluruh siswa dan guru secara berkelanjutan. Perlu dilakukan pendampingan operasional sistem informasi perpustakaan agar aplikasi dapat dimanfaatkan secara berkesinambungan. Kegiatan ini dapat ditindaklanjuti dengan bentuk kerjasama pengembangan beberapa sistem sekolah terintegrasi.

\section{UCAPAN TERIMA KASIH}

Pengabdian pada masyarakat ini didukung oleh Direktorat Riset dan Pengembangan Kepada Masyarakat (DRPM) Institut Teknologi Sepuluh Nopember Surabaya dengan nomor Surat Perjanjian Pendanaan 1059/PKS/ITS/2020, tanggal 02 April 2020. Kami berterima kasih kepada DRPM-ITS atas dukungannya untuk mempublikasikan makalah ini pada jurnal nasional. 


\section{DAFTAR PUSTAKA}

Arief, M. R. (2011). Pemrograman Web Dinamis Menggunakan PHP dan MySQL. Yogyakarta: Andi.

Indera, R. (2015). Pengembangan sistem informasi penjualan alat kesehatan berbasis web pada Pt. Alfin Fanca Prima. Positif: Jurnal Sistem dan Teknologi Informasi, 1(1), 37-45.

Kustiyahningsih, Y., \& Rosa, D. (2011). Pemrograman Basis Data Berbasis WEB Menggunakan PHP dan MySQL. Yogyakarta: Graha IImu.

Nugraha, F. (2014). Analisa dan perancangan sistem informasi perpustakaan. Simetris: Jurnal Teknik Industri, Mesin, Elektro dan Ilmu Komputer, 5(1), 27-32. https://doi.org/10.24176/simet.v5i1.132

Oktami, A. S., \& Mailoa, E. (2019). Perancangan sistem informasi data pelayanan pengunjung berbasis web menggunakan framework Codelgniter dan Ulkit (Studi kasus: Perpustakaan dan arsip daerah Kota Salatiga). JBASE - Journal of Business and Audit Information Systems, 2(1), 15-23. http://dx.doi.org/10.30813/.v2i1.1499

Pressman, R. S., \& Maxim, B. (2014). Software Engineering: A Practitioner's Approach, 8th edition. New York: McGraw-Hill Education.

Rahmawati, N. A., \& Bachtiar, A. C. (2018). Analisis dan perancangan sistem informasi perpustakaan sekolah berdasarkan kebutuhan sistem. Berkala Ilmu Perpustakaan dan Informasi, 14(1), 76-86. https://doi.org/10.22146/bip.28943

Renatha, F. A., Satoto, K. I., \& Nurhayati, O. D. (2015). Perancangan dan pengembangan sistem informasi perpustakaan berbasis web (Studi kasus jurusan sistem komputer). JTSISKOM: Jurnal Teknologi dan Sistem Komputer, 3(3), 343-353. https://doi.org/10.14710/jtsiskom.3.3.2015.343-353

Rohmah, N., Aryadita, H., \& Brata, A. H. (2019). Pengembangan sistem informasi perpustakaan berbasis web pada perpustakaan Kecamatan Bungah. JPTIIK: Jurnal Pengembangan Teknologi Informasi aan Ilmu Komputer, 3(3), 2225-2234.

Suhartini, S., Sadali, M., \& Putra, Y. K. (2020). Sistem informasi berbasis web SMA Al-Mukhtariyah Mamben Lauk berbasis PHP dan MySQL dengan framework Codeigniter. Infotek/ : Jurnal Informatika dan Teknologi, 3(1), 79-83. https://doi.org/10.29408/jit.v3i1.1793

Susanti, M. (2016). Perancangan sistem informasi akademik berbasis web pada SMK Pasar Minggu Jakarta. Jurnal Informatika, 3(1), 91-99. https://doi.org/10.31294/ji.v3i1.304

Yahya, H. A. Q. (2020). Rancang bangun aplikasi perpustakaan menggunakan framework Code Igniter (Studi kasus SDN Cibubur 05). Jurnal Sistem Informasi dan Sains Teknologi, 2(2), 4-13. https://doi.org/10.31326/sistek.v2i2.663 